teeth has a distinct value. The teeth are solid, and, in the "Norse" type, massive. They are blunt and thick at the edges, and worn down. They have a great tendency to come out without any caries, but from an osteitis, extending from the neck along the fang to the root. Several of such teeth are attached to the card handed round. It will be seen that the incisor tooth is more worn down than the canine or molar teeth are. The centre of the tooth-surface is also of dark colour. When the gouty patient, on request, shows his or her teeth, their build and conformation are usually at once to be detected; while often the gum is seen retracted. Sometimes the front teeth of the upper jaw are very massive. The osteal growth along the fang of the canine tooth exhibited is very well marked. The teeth exhibited are not large, though they came from a massive gouty man of the "Norse" type. It is almost superfluous to say that these teeth did not trouble the dentist in their exodus from the jaw. Some years ago the subject of "gouty teeth" was mentioned by me at the Harveian Society, upon which Dr. William Stewart took casts of the teeth of a number of his undoubtedly gouty patients. He showed them before the Harveian Society, when it was decided that the teeth did manifest more or less of the peculiarities just mentioned. By his courtesy I am enabled to exhibit these casts to you to-day, so that you can express your own opinion on the subject. One cast, showing the teeth in a comparatively early stage, I have had engraved (see Fig. 1). They are

FIG. 1.

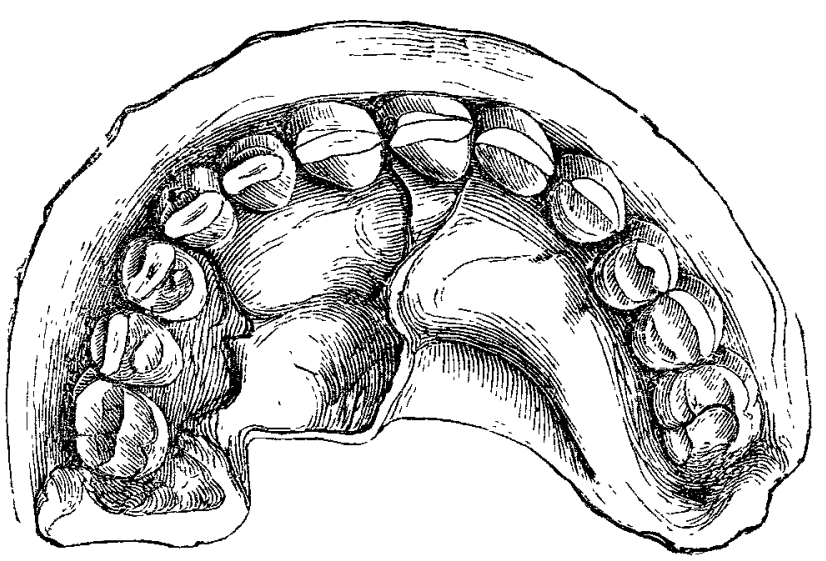

regular, well shaped, solid, if not large, teeth, beginning to wear down distinctly on the surface. Such worn-down teeth, in my experience and opinion, belong to gouty persons.

Another matter is the nails. Sir Charles Scudamore long go observed a peculiar hardness or brittleness of the nails of the gouty, so that it was difficult to keep them well trimmed. After some attention to the subject, I have come to the conclusion that the nails in gouty persons soon lose their smoothness, and become "reedy" or striated, showing the indiridual hairs of which the nail is built up. The photograph before you shows a "reedy" nail from a lady who is gouty. (Fig. 2, A). The others (B and $\mathrm{C}$ ) have an

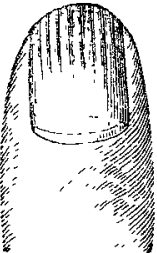

A

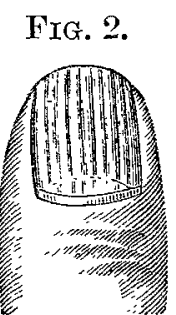

$\mathbf{B}$

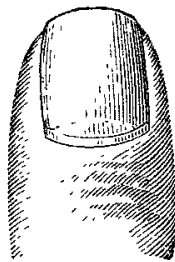

C interesting history. A gentleman present (Dr. Archibald) consulted me a year ago about his gout, for which I prescribed. After being put upon treatment, he observed the change in his nails. They lost their roughness and their reediness, and grew perfectly smooth. When just half-way grown, the distal half being " reedy," while the proximal end was quite smooth, I had the thumb-nail photographed; and the difference is at once obvious. Later on, when the new nails were fully grown, another photograph (c) of the same nail was taken, and it will at once be seen that the nail is smooth and normal, and has lost its gouty characteristics. Not having a photograph of the nail (A) before the anti-gout treatment was adopted, a thumb-nail of a person of like age, and bearing a very close resemblance to it, has been taken in its place."

Now I do not ask you to do more than consider these matters and express your opinion thereon. Are we in a position to say that any person has gout when complaining of maladies experience has taught us are frequently the outcomes of gout? Is there sufficient evidence for a committal? Can we from the build, the contour, the ear, the teeth, the nails, plus a certain irritability at times felt by the individual, say that gout is underlying the phenomena complained of ? $^{5} 1$ hold that very often it is possible to say that a person is gouty, or, in other words, the subject of hepatic reversion, despite the absence of any articular evidence thereof.

\section{A CASE OF VAGINAL LITHOTOMY;}

WITH REMARTS ON STONE IN THE FEMALE AS IT OCCURS AT THE NORFOLK AND NORWICH HOSPITAL,

BY CHAS. WILLIAMS, F.R.C.S. EDIN., SURGEON TO THE HOSPITAL.

S. C-- aged sixty-one, was admitted into the Norfolk and Norwich Hospital, under my care, in December, 1882, suffering from stone in the bladder. She was tall and much emaciated, and her general health greatly impaired by the severe sufferings she had experienced during the previous twelve months. She appeared to be almost worn out by pain and want of sleep. She could not assume the erect posture, her pain being much aggravated thereby; and she had also complete incontinence of urine. Jrior to a year ago the symptoms were not very marked. During the past few months, however, she had voided thirteen small grey calculi. The urine was faintly acid, sp. gr. 1015, and contained mucus and pus in large quantity. Her maternal grandfather suffered from stone in the b]adder.

The passage of a sound readily detected the presence of a large calculus, on which the bladder had firmly contracted it formed a large smooth tumour projecting into the vagina, and completely occluded this passage. She was very anxious to be relieved of her trouble, and about two weeks after admission she was placed on the operation table, a straight staff was passed into the bladder under the stone, a long incision made in the resico-vaginal septum from its posterior part forwards to within a short distance of the urethra, and with some amount of difficulty the calculus was dislodged and extracted through the opening. The amount of hæmorrhage was very trifling. The wound was sewn up with a continuous suture of green gut, a catheter placed in the bladder, a suppository containing half a grain of morphia inserted into the rectum, and one grain of extract of opium given by the mouth. The calculus was of a flattened oval form, and consisted of uric acid and urates conated with a thick, dense layer of phosphates; it weighed $7 \mathrm{oz}$, and measured $8 \frac{1}{4} \mathrm{in}$. in its longest circumference, $6 \frac{1}{2} \mathrm{in}$. in its shortest, $23 \mathrm{in.}$ in its largest diameter, and $2 \frac{1}{2} \mathrm{in}$. in its shortest. In the evening a fair amount of rery bloody urine had passed. She was in no pain. The skin was warm and perspiring. The next day there was an abundance of urine. On the fourth day she was very comfor able; on the eighth day a good deal of urine had escaped into the bed; on the ninth day all the urine ran into the bed, and none came through the catheter, which was removed, as it was evident enough that the wound had opened. She went on very well until the sixteenth day, when the report states: "She takes food well. There is slight diarrhas, and plenty of urine, which is not offensive. She had a rigor this evening." From this time she gradually sank, and died on the eighteenth day.

Examination of the body after death showed that the right kidney was enlarged to three times its natural size the pelvis was converted into a large abscess sac, and contained thick pus; the ureter from this kidney, at about two inches from its origin, was firmly blocked by a calculus. The left kidney was considerably hypertrophied; its structure

4 I saw that lady this afternoon, and the reediness of the engraving is no exaggeration of her nails.

5 Of course there are many nther points to be noted-as Garrod's uric acid thread test-before the diagnosis can be regarded as completely made out.

A paper read at the Norwich Medico-Chirurgical Society. 
was tolerably healthy; there was scarcely any dilatation of its pelvis. The other organs were not examined.

Remarks.-Stone in the bladder of the female is by no means a common disorder. The records of the Norfolk and Norwich Hospital from 1771 to 1884 , a period of 113 years, show that of 1234 cases of stone admitted into that institution and operated upon, only 5.2 of this number occurred in females; this gives a proportion of 1 female to 24 males. On an average 1 female is admitted about every two years; whereas in the same space of time 21 males are, on an average, admitted with that complaint. Of the 52 cases, 3 were caused by the introduction of foreign bodies into the bladder by the females themselves, the hair-pin being the favourite instrument used. The character of the stones in all these cases was phosphatic. Among the 52 cases no stone was removed comparable to the size of the one I took from this woman. The next in size weighs $5 \frac{1}{2} \mathrm{oz}$., and was removed in 1773 from a female aged twenty-nine, who recovered. This was the first female operated on at the hospital. Cure was effected in 48 of the cases ; 4 died ; the rate of mortality being nearly 1 in 11. The ages of those who died were as follows: One of twelve years, whose calculus weighed $2 \mathrm{drs}$, and consisted of uric acid and urates. The next was fifty-three years of age; the stone weighed $3 \frac{1}{4} \mathrm{oz}$., and consisted of mixed phosphates. The third was sixty-one years of age; she had two stones in her bladder, one of which was free, the other sacculated; both weighed $4 \mathrm{drs}$ The fourth case, aged sixty-one, is the subject of this paper. Of the 52,14 occurred under ten years of age, 10 from ten to twenty, 10 from twenty to thirty, 5 from thirty to forty, 4 from forty to fifty, 4 from fifty to sixty, and 5 from sixty to seventy. There were 34 under thirty years of age, and 18 from thirty to seventy. The ages of the hair-pin cases were seventeen, twenty-one, and twenty-two. In 15 cases the calculi weighed 1 oz. and over, 8 consisting of phosphates and 7 of urates; the rest were under that weight. In one woman, whose age was fifty, the stone weighed only 4 grs. In no case did a relapse of stone take place. In 50 females, only one stone was found in every bladder; in 2 females, two stones were found in each bladder. In twenty-one cases the calculi consisted of uric acid and urates; in twenty-one, of mixed phosphates; in 7 , phosphates and urates; the rest, mixed.

So far as I can ascertain, this is the first time that a case of stone in the female bladder has been operated on by vaginal lithotomy at the Norwich Hospital. The specimens of calculi removed from the fifty-two females are preserved in the museum attached to the institution, and to every one is appended the word "extracted." I presume that this word signifies removed by means of dilatation, with probably division of the urethra, or else division of the urethra without dilatation. Unfortunately there are no records at the hospital to indicate what was the precise nature of the operation performed on females at that period. The only allusion to the subject in Mr. J. G. Crusse's work on Calculus is contained in the following passage: "Female patients were at an early date operated on by cystotomy, but of late years all calculi from the bladders of females have been removed by dilatation." What the operation "cystotomy" was there is no evidence to show. Mr. Crosse does not describe what he means by that term - a term which simply signifies the operation of opening the bladder, be it male or female, for the extraction of the stone. The word itself does not indicate any exact kind of operation, so we are left in the dark as to what was done by our forefathers at this hospital.

It is supposed that vaginal lithotomy is an operation of modern date; it certainly is one rarely performed, inasmuch as Dr. Aveling, in an excellent paper on the subject, printed in the Obstetrical Transactions for 1863, could not find more than thirteen cases published in British surgery, and twentytwo in foreign. Curiously enough, three of the thirteen cases are recorded by a Norfolk surgeon, Benjamin Gooch, with whom the operation seems to have originated. In his work on Surgery, dated 1767, he states as follows:-

"Mrs. T-..., aged between forty and fifty, after having been severely afflicted with the stone for about ten years, resolved to submit to the operation, should it be thought advisable, her constitution being much impaired, and having a constant discharge of purulent matter from her bladder. On August 17th, 1740, she asked my advice, and, after well considering all her complaints, I was of opinion that it was right to extract the stone, though the event of the operation could not but be looked upon as very pre- carious, for by passing my finger up the vagina uteri I could plainly discover it was of a large size, the friction of which had caused inflammation and ulceration of the bladder. After putting her in the usual posture for the operation, I intended to have proceeded in the common manner, by dilating the urethra, and making an incision as should be found necessary to facilitate the extraction of the stone; but finding with my finger that it lay very favourably to be cut upon through the vagina uteri, now considerably dilated, I altered my original design, and, with the approbation of two experienced practitioners, cut directly upon it and extracted it, with very little pain to the patient or trouble to myself, compared with what a stone of between three and four ounces' weight must unavoidably have occasioned by performing the operatiun in the common method. The symptoms after the operation were the most gentle; the ulceration of the bladder soon healed by soft balsamic injections, and she was perfectly cured in three weeks, without any defect remaining in the retentive faculty. I have since been concerned with other surgeons in two cases similar to this who were induced to practise the same method, and which succeeded as happily."

Benjamin Gooch was appointed the first consulting surgeon to the Norfolk and Norwich Hospital when it was established in 1771. Whether the early hospital surgeons practised the operations as devised by him there is no evidence to inform us.

\section{g. altirrox}

\section{H OSPITAL PRACTICE, BRITISH AND FOREIGN.}

Nulla autem est alia pro certo noscendi via, nisi quamplurimas et morborum et dissectionum historias, tum aliorum tum proprias collectas habere, et inter se comparare. - MORGAGNI De Sed. et Caus. Morb., lib. iv. Procemium.

ROYAL HOSPITAL FOR WOMEN AND CHILDREN.

LARGF MULTILOCULAR OVARIAN CYST; OVARIOTOMY; CURE.

(Under the care of Dr. WILLIAM DUNCAN.)

OVARIAN tumours always present considerable interest to the surgeon, and the one in the following case is especially interesting. In the first place, its resemblance to a normal pregnancy appears to have been such as to mislead the medical man in charge of the case. And in the second the oozing of ascitic fluid from the umbilicus presents a condition of extreme rarity, of which there are comparatively few examples on record.

Mrs. S-, aged twenty-eight, married two years, no children or miscarriages, was admitted on July 5th, 1884 . The patient states that the catamenia began at the age of thirteen; she was always regular until January, 1884; since then she has had amenorrhoea. In July, 1883, she first noticed that her abdomen was swelling; two months later morning sickness came on and continued for ten months. The swelling has rapidly increased during the last three months. Two months before admission she had pains in the back and in the abdomen. The patient says she used to feel something moving "in her inside" till two months ago. She firmly believes herself to be pregnant. Seven weeks ago a blister formed on the umbilicus, and began to discharge a yellowish transparent fluid. This discharge continued until her admission. The patient is a sallow, emaciated woman, with a distended abdomen. The umbilicus is swollen and protruding, with a yellowish fluid oozing continuously drop by drop from it; the surrounding skin is inflamed. The abdomen is occupied by a firm and somewhat elastic swelling, reaching above as far as the ensiform cartilage, and in front and on the left side to the costal arch; the right side is not so fully occupied by the tumour, this flank being resonant; the left is quite dull. The tumour is rounded and smooth in the lower part, but above the umbilicus several irregular semiglobular portions are felt, and on the left side, below the ribs, a firm rounded mass can be seized, as big as a fotal head, which, when grasped and moved, moves the whole tumour. There is obscure fluctuation in some parts, but on the left side, between the umbilicus and the left anterior superior spine, the 